\title{
Future Emerging Issues in waterborne diseases and microbial agents
}

\author{
Sherchand J B \\ Department of Medical Microbiology and Public Health Research Laboratory \\ Tribhuvan University Institute of Medicine, Kathmandu, Nepal
}

Infectious water related diseases are a major cause of morbidity and mortality worldwide. Newly-recognized pathogens and new strains of existing pathogens are being discovered that present important challenges to both water and public health sectors- between 1972 and 1999, 35 new agents of disease were discovered and many more have reemerged after long periods of inactivity or are expanding into areas where they have not previously been reported.

Relevant water-related pathogens have included Escherichia coli O157:H7, Giardia, Cryptosporidium, Cyclospora, hepatitis E virus and legionella. Others now being evaluated include Helicobacter pylori. Drivers of emergence of 'new' pathogens include microbial evolution, creation of new environments introduction of new technologies and developing abilities to detect and study the microorganisms themselves ${ }^{1,2}$.

In 2003, Sharma et $\mathrm{al}^{2}$ have defined an emerging pathogen as "any new, reemerging, or drug resistant infection whose incidence in humans has increased within the past two decades or whose incidence threatens to increase in the future." This definition is derived from a report published by the Institute of Medicine of the National Academies in the USA in $1992^{3}$. In 2003, Smolinski et al have published another work entitled Microbial Threats to Health: Emergence, Detection and Response to address current concerns associated with emerging pathogens ${ }^{4}$. Emerging pathogens are characterized by their increasing prevalence and have the potential to become endemic, epidemic, and even pandemic in nature. Clinical illness associated with these emerging pathogens, compared with other closely related pathogens, may be more severe, transmitted more rapidly or widely within populations, or more difficult to prevent or treat ${ }^{5}$.

Many classes of pathogens excreted in feces are able to initiate waterborne infections. There are bacterial pathogens, including enteric and aquatic bacteria, enteric viruses, and enteric protozoa, which are strongly resistant in the water environment and to most disinfectants ${ }^{6}$. The infectious dose of viral and protozoan agents is lower than bacteria, in the range of one to ten infectious units or oocysts. Waterborne outbreaks of bacterial origin (particularly typhoid fever) in the developing countries have declined dramatically from 1900s. However, some early bacterial agents such as Shigella sonnei remain prevalent and new pathogens of fecal origin such as zoonotic Campylobacter jejuni and E. coli O157:H7 may contaminate pristine waters through wildlife or domestic animal feces. These bacteria even in low inoculums (few hundred cells) have the capacity and trigger disease. In early 1992 the emergence of serotype O139 of Vibrio cholerae with epidemic potential in Southeast Asia suggests that other serotypes other than V. cholerae O1 could also trigger on epidemic ${ }^{7,8}$. Some new pathogens include environmental bacteria that are capable of surviving and proliferating in water distribution systems. The general population is refractory to infection with ingested Pseudomonas aeruginosa, however specific hosts are still at risk. The significance of Aeromonas spp. in drinking water to the occurrence of acute gastroenteritis remains a debatable point and has to be evaluated in further epidemiological studies. Legionella and Mycobacterium avium complex (MAC) are environmental pathogens that have found an ecologic niche in drinking and public water supplies. Numerous studies have reported Legionnaires' disease caused by L. pneumophila occurring in residential and hospital water supplies. M. avium complex frequently causes disseminated infections in AIDS patients and drinking water has been suggested as a source of infection; in some cases the relationship has been proven ${ }^{9}$. More and more numerous reports show that Helicobacter pylori DNA can be amplified from feces samples of infected patients, which strongly suggests fecal-to-oral transmission. Therefore, it is possible that $\mathrm{H}$. pylori infection is waterborne, but these assumptions need to be substantiated. Giardiasis has become the most common cause of human waterborne disease in developed and developing countries. The transmission of Cryptosporidium and Giardia through treated water supplies that meet water quality standards demonstrates that water treatment technologies have become inadequate, and that a negative coliform no longer guarantees that water is free from all pathogens, especially from protozoan agents. Substantial concern persists that low levels of pathogen occurrence may be responsible for the endemic transmission of enteric disease. In addition to Giardia and 
Cryptosporidium, some species of genera Cyclospora, Isospora, and of family Microsporidia are emerging as opportunistic pathogens and may have waterborne routes of transmission ${ }^{10,11}$. More than 15 different groups of viruses, encompassing more than 140 distinct types can be found in the human gut. Some cause illness unrelated with the gut epithelium, such as Hepatitis A virus (HAV) and Hepatitis E virus (HEV). Hepatitis E is mostly confined to tropical and subtropical areas, but recent reports indicate that it can occur at a low level in Europe. A relatively small group of viruses have been incriminated as causes of acute gastroenteritis in humans and fewer have proven to be true etiologic agents, including rotavirus, calicivirus, astrovirus, and some enteric adenovirus ${ }^{12,13}$. These enteric viruses have infrequently been identified as the etiologic agents of waterborne disease outbreaks, because of inadequate diagnostic technology, but many outbreaks of unknown etiology currently reported are likely due to viral agents. Actually, Norwalk virus and Norwalk-like viruses are recognized as the major causes of waterborne illnesses world-wide. The most striking concern is that enteric viruses such as caliciviruses and some protozoan agents, such as Cryptosporidium, are the best candidates to reach the highest levels of endemic transmission, because they are ubiquitous in water intended for drinking, being highly resistant to relevant environmental factors, including chemical disinfecting procedures. Other concluding concerns are the enhanced risks for the classic group of debilitated subjects (very young, old, pregnant, and immunocompromised individuals) and the basic requirement of to take specific measures aimed at reducing the risk of waterborne infection diseases in this growing, weaker population ${ }^{14}$.

Moreover, numbers of new risks for waterborne zoonotic diseases are identified, in which the concern authorities need to be able to respond in a scientifically based manner to address the threat where it occurs. This will require cooperation, sharing of information and resources, sound risk assessment, and multiple prevention and control strategies that are scalable and can be applied in lowand high-resource environments. Increased risks of the transmission of waterborne diseases can be related to mobility of population, high density and close proximity of domestic animal and human populations, agricultural practices, heavy rainfall events, and demographic factors. Improved surveillance and monitoring and greater commitments to sanitation and water management are needed to detect global and ecological changes and to ensure protection from associated re-emerging and emerging infectious diseases.

\section{References:}

1. Sherchand JB, Cross JH. Emerging pathogen Cyclospora cayetanensis infection in Nepal. South East Asian J Trop Med Public Health 2001; 32: 143150.

2. Sharma S, Sachdeva P, Virdi JS. Emerging water-borne pathogens. Appl Microbiol Biotechnol 2003; 61(5-6), 424-428.

3. Lederberg J, Shope RE, Oaks SC. Emerging Infections. Microbial Threats to Health in the United States 1992; 312 pp., National Academy Press, Washington, DC.

4. Levett PN. Leptospirosis. Clin Microbiol Rev 2001; 14(2), 296-326.

5. Smolinski MS, Hamburg MA, and Lederberg J. Microbial Threats to Health: Emergence, Detection, and Response. 2003; 398 pp., National Academy Press, Washington, DC.

6. WHO/ UNICEF. Global water supply and sanitation assessment 2000. Report 2000; World Health Organization, Geneva.

7. Marshall MM, Naumovitz D, Ortega Y and Sterling CR. Waterborne protozoan pathogens. Clin Microbiol Rev 1997; 10(1), 67-85.

8. Morabito S, Tozzoli R, Oswald E and Caprioli A. A mosaic pathogenicity island made up of the locus of enterocyte effacement and a pathogenicity island of Escherichia coli O157:H7 is frequently present in attaching and effacing E. coli. Infect Immun 2003; 71(6), 3343-3348.

9. Morita S, Namikoshi A, Hirata T, Oguma K, Katayama H, Ohgaki S, Motoyama N and Fujiwara M. Efficacy of UV irradiation in inactivating Cryptosporidium parvum oocysts. Appl Environ Microbiol 2002; 68(11), 5387-5393.

10. Hrudey SE, Payment P, Huck PM, Gillham RW and Hrudey EJ. A fatal waterborne disease epidemic in Walkerton, Ontario:comparison with other waterborne outbreaks in the developed world. Water Sci. Technol 2003; 47(3), 7-14.

11. Biswas K, Craik S, Smith DW and Belosevic M. Synergistic inactivation of Cryptosporidium parvum using ozone followed by free chlorine in natural water. Water Res 2003; 37(19), 4737-4747.

12. Wright MS and Collins PA. Waterborne transmission of Cryptosporidium, Cyclospora and Giardia. Clin 
Lab Sci 1997; 10(5), 287-290.

13. Cross JH, Sherchand JB. Waterborne Zoonoses: Identification causes and control. WHO book, Edited by JA Cotruvo A, Dufour G, Rees J, Bartram $\mathrm{R}$ et al., Published by IWA Publishing, London, UK. ISBN: 1843390582.

14. Sherchand JB, Cross JH. Cyclospora cayetanensis in Nepal:A study of microbiological and epidemiological aspects. Journal of Nepal Health Research Council 2003; 3: 1-8.

15. Gofti ML, Zmirou D. and Seigneurin JM. Detection of human and animal rotavirus sequences in drinking water. Appl Environ Microbiol 2000; 66(6), 2690-2692.

16. Van Der Poel WH, Vinje J, van Der Heide R, Herrera MI, Vivo A. and Koopmans MP. Norwalk-like calivirus genes in farm animals. Emerg Infect Dis 2000; 6(1), 36-41. 